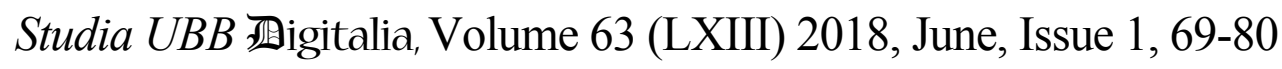

Published Online: 2018-06-30

DOI:10.24193/subbdigitalia.2018.1.05

\title{
Measuring Physical and Virtual Presence in the digital economy era
}

\author{
Romeo Stanca, Rodica Sobolu \\ Babeș-Bolyai University, Cluj-Napoca \\ USAMV, Cluj-Napoca
}

\begin{abstract}
In the present study, we analyze the students' reaction to the introduction of Web 2.0 as teaching-learning environment in digital economic theory, in a society where the internet was introduced in 1990. The article is the result of a research extended over two years. The research focuses on the study of behavior observed to the students with computer usage knowledge in relation to the translation of their activities on Moodle platform. The students belong to a department of Economics Informatics of a Romanian University. Specifically, we sought if Moodle with its facilities to assist/guide the student in the learning process can increase the percentage of those who will assimilate knowledge of databases theory apply in economic fields, compared to traditional ways of teaching. The outcome of this study can be considered favourable on Moodle application.
\end{abstract}

Keywords: digital economic theory; Weeb 2.0; behaviour analysis; learning analytics, digital skills

In the present study, we analyze the students' reaction to the introduction of Web 2.0 as teaching-learning environment in digital economic theory, in a society where the internet was introduced in 1990. The article is the result of a research extended over two years. The research focuses on the study of behavior observed to the students with computer usage knowledge in relation to the translation of their activities on Moodle platform. The students belong to a department of Economics Informatics of a Romanian University. Specifically, we sought if Moodle with its 
facilities to assist /guide the student in the learning process can increase the percentage of those who will assimilate knowledge of databases theory compared to traditional ways of teaching. The outcome of this study can be considered favourable on Moodle application.

\section{Introduction}

According (C.C. Aydin, G. Tirkes), ( K. Brandl) learning computer science with the help of collaborative tools like Moodle requires development of learning communities in which individuals share their experience acquired during projects. In our study we present how Moodle can help in teaching computer science. Moodle has been chosen by our department to be implemented in all the disciplines. Moodle is designed on the socio-constructivist pedagogy (S. Bianchi, et all). This means that its purpose is to provide a set of tools to support investigation and an approach based on the discovery learning process. We believe that the learning process in computer science is perfectly suited to this theory. So, while Moodle is designed on this theory, Moodle will be more suited to the need of creating an open source community for learning computer science, idea supported also in (C.C. Aydin, G. Tirkes), (S. Bianchi, et all). Next we present a study of generating/discovering the student's behaviour in two of our courses. In one, we use Moodle to teach computer science for amateurs and in the other one we use Moodle for teaching English also for non-professionals. We decided that this study could be done as it imposes the same mechanisms for computer science learning and learning a foreign language.

In order to spread education, many universities of the world have been implemented Moodle learning environment system. Open University from Great Britain became the second largest user Moodle, with 607,536 registered users and 4731 courses. University of Malaga, Spain uses Moodle module for teaching practical of basic computer course (K. Brandl), University of Padua, Italy has developed English course for librarians services (D.L. Davids). University of Pune, India implemented Moodle in Library and Information Science Department (C.C. Aydin, G. Tirkes).

In the period 2000-2001, there were first initiatives for Romania to adapt EU Strategy for Development with particular emphasis on higher education and creating the necessary infrastructure for the implementation and development of e-learning. Then, in 2007, after Romania's accession at the European Union, its efforts in this area have increased. At the present, according to (K. Brandl), (D.L. Davids), most universities seem to have an infrastructure necessary for the implementation of e-learning, focused on management courses. Currently, in Romania many efforts are being made to study the 
degree of the availability of both, teachers and students to transfer learning in an online environment. In this research area our study falls. According [8], e-learning platforms are used by students in order achieve both, personal or professional purposes. Also, students have access to e-learning platforms in the faculties where he studied. The research exposed in (P. Griffin et all), $\left({ }^{* * *}\right.$ Moodle) show that the Romanian universities are concerned include to include Web 2.0 technologies in various teaching subjects. Moodle for e-learning course management system was implemented too in Romanian Education System. Many Romanian Universities are using Moodle platform for distance learning programs (Babes-Bolyai University, Cluj-Napoca, Transylvania University, Brasov, University for Agricultural Sciences and Veterinary Medicine, lasi, University for Agricultural Sciences and Veterinary Medicine, Bucuresti, Agora University, Oradea, Vasile Goldis University, Arad), for students teaching training (Babes-Bolyai University), Postdoctoral School of Biotechnology (University for Agricultural Sciences and Veterinary Medicine, Cluj-Napoca).

Today, in Romania more and more students are accessing and using the Moodle platform and their facilities in the learning-teaching process. It is important to monitor the impact of this learning tool to quantify the amount of acquired knowledge in more and more areas. Moodle facilities are considered for Romanian teachers training (S. Bianchi, et all). The impact of this modern tool for learning-teaching process was analyzed in mathematics field (C. Felea, L.Stanca).

In the literature, the Moodle's impact in the learning process has been investigated by many specialists of whom we tried to fit the results obtained in the research a long aside

1. Escobar-Rodriguez and (T. Escobar-Rodriguez, P. Monge-Lozano) who analyzed students' intention to use platforms like Moodle to improve the teaching-learning process at the Technical University of Madrid. The result of their study shows that students believe that Moodle help them to improve their knowledge and skills.

2. Paragina et al (F. Paragina, et all),( S. Paragina, et al) in their study concluded that the management of a course through Moodle is a very complex activity which requires that people who use Moodle have to have very good knowledge of the platform on which to add then the e-learning skills.

3. In (C. Felea, L. Stanca) it is concluded that the learning tools based on IT technologies allow a flexible and interactive learning experience that institutions use to offer a high education, personalized for each category of students. According to (C. Felea, L. Stanca) student's needs in the global context require fast access to the information that eventually allows fast learning. In online courses, all statements are mediated by technology; in most cases this is a Learning Management System (LMS) such as Moodle. 
4. In the literature, specifically in articles (G. Grosseck) (C. Felea, L. Stanca 2013), (C. Felea, L. Stanca 2014), (R. Lacurezeanu, et al),( A. M. Preda, et al.), ( E. Popescu, D. Cioiu) efforts are focused to measure the degree of involvement of the students, the teacher being by default involved, in the educational process with Moodle's help. The involvement of the teacher is considered high due to his efforts to deliver material and organize the entire course management system. In (T. Escobar-Rodriguez, P. Monge-Lozano) it is studied whether teachers who develop such platforms have the attributes and behavior their students require: the enthusiasm for the subject and for teaching, the commitment to give to students the appropriate support in their learning process, its interest in getting directly involved in the learning process of students and find ways to help them learn.

This study will examine the involvement of students from the real domain in a specific course where Moodle has been introduced in the last year. In this context in the process of creating the teaching materials, we tried to answer the demands of the technological progress, which caused a large number of modern teaching methods: meaningful learning, collaborative learning, inquiry learning, etc. These methods promote the so-called competences of the XXIst century (21st Century Life Skills), ie creativity, critical thinking, collaboration ability and problem solving skills. Technology has eliminated physical boundaries of the country, so students need to have the skills to be able to turn both into global citizens as well as employees acting in global companies where there is a wide range of cultures that are necessary to live together in harmony to achieve success (P. Griffin) As a result of this development according to (M.A. Trenas, et al.), a teacher must design teaching materials and to organize the whole process of teaching and learning so that students are given a complex framework that promotes both structured and collaborative and individual learning. Consequently, the student will have to solve problems deeply rooted in the labour market, which require both individual and team work. The purpose of these scenarios is to simulate a working environment in which the student must be able to make and take decisions personally and collectively which they then assume regardless if they lead to success or failure. Reaching the goal required the development of a whole process of developing teaching material and course structure, as follows:

1. We joined the beliefs / ideas of (A. Bullimore, Q. Bullimore) whereby education through skills training is based on several principles: defining and developing skills for an appropriate socio-professional insertion or for the formation of mental abilities in different situations; integration of knowledge rather than individual acquisition; orientation to learning complex tasks; selecting motivating and challenging situations for the student to make significant; the assessment in an explicit way by proposing complex task; 
2. According to (S. Bianchi, et al) education focused on skills creates opportunities for students through which they can develop integrated skills, performance-oriented, giving necessary and sufficient knowledge to solve various practical problems;

Following the effort to develop and align materials to a collaborative environment like Moodle we obtained a research that spanned over two years where we watched the new student reaction, measuring the degree to which he is prepared to extract information at his own pace.

Student's behaviour considered in digital economy implemented on Moodle. The course content will be exposed to the students in the classroom using power point presentations. The applied section of the discipline, organized as seminar takes place in laboratories equipped with computers. The course content is divided into 14 studied weeks. Every week there is a course and a seminar. At the course section, the teacher presents the theoretical concepts combined with practical examples. The seminars also comprise practical examples, starting from the course's theory. From both the course and the seminar homework is formulated. Homework will be resolved after completing the course information, the seminar examples and the bibliography. Each student hands a written homework to his teacher. The homework will be corrected and assessed by teacher. Also, each student will present to his colleagues an original project. The project theme will be chosen starting from the bibliography. In assessing the project it will be considered the originality, bibliography's compliance and presentation style.

The participants at this study are individuals who have medium or high level knowledge (formation) in the use of computers. The purpose of the course is to provide to the students the database theory. This topic is essential for a student at a business faculty. In the first year of the Moodle implementation at our faculty, both the teachers and the students were in the first stage of a special tool use in their activity. In the second year, the teacher better knows this teaching environment, and thus he can provide additional information to his students. The teacher acquires an overview of the respective strengths or weak points of the Moodle instrument use in learning-teaching process.

\section{Material and methods}

\subsection{Research Objective}

The assumptions of this study focus on the observation of the student who has ITC knowledge, in the context of learning-teaching activities translated on online Moodle platform. Specifically, we sought if Moodle with its facilities to assist /guide 
the student in the learning process can increase the percentage of those who will assimilate knowledge of scripting language compared to previous years.

\subsection{Method}

The study was done on 124 students of the economic field for a period of two consecutive years. The first year of the study overlaps with the time when the Moodle platform was implemented in our department. Student's behaviour hypothesis analysis to Moodle changes from one generation to another.

Data was collected using logs on to Moodle platform. The data aim to quantify the students' interaction with the Moodle course page via views components. For the first year of study was chosen time period from October 2015 to February 2016. For the second year of study of the same students, period October 2016 to February 2017 was chosen. Analysis was designed in two stages. The first stage comprises dynamic of page views calculated for groups with different level of computer usage within each academic year. The results of the first stage generated the second step of the analysis. In this moment the medium level and the advanced level of usage computer was compared in the two consecutive academic years considered. In order to test statistical hypothesis SPSS 13.0 application was used. First we applied the Kolmogorov-Smirnov normality test. Then, based on the results of this test, we chose further nonparametric Mann-Whitney test, correlation and regression analysis and Kruskal-Wallis test.

Analysis of data collected via questionnaire provides the following conclusions: of the amount of 124 students surveyed $81.5 \%$ are female, while $18.5 \%$ are male. Also, from the total specified, $57.7 \%$ have a medium level of usage computer and the remaining $42.3 \%$ have an advanced level of usage computer. Regarding the interest for database theory, we conclude that: $45.6 \%$ have low interest, $27.8 \%$ average interest and the remaining of $26.6 \%$ have high interest.

The recorded data provides for the first year of study the following results: $50 \%$ of students show low interest, $27 \%$ have average interest and $22.2 \%$ exhibit a high interest for the study of database theory. Regarding the level of knowledge in computer usage we established: $55.6 \%$ have medium level of knowledge and the remaining of $43.5 \%$ has a medium to high level of knowledge in computer usage. Also, the average mark obtained for the seminar participants was 5.73 and the corresponding standard deviation was 2.31. The average values recorded via view inputs during DecemberJanuary period were: October 0.87, November 2.6, December 3.24 and

January 3.16. Corresponding standard deviation was respectively: October 1.26, November 2.93, December 2.73 and January 4.11. 
Regarding the 2nd year of study we concluded that $41.1 \%$ of students show low interest, $30.6 \%$ have average interest and $58.9 \%$ exhibit a high interest for the study of database theory. The level of knowledge in computer usage provides the following percentages: $58.9 \%$ have medium level of knowledge and the remaining of $41.1 \%$ has a medium to high level of knowledge in computer usage. Also, the average mark obtained for the seminar participants was 6.54 and the corresponding standard deviation was 2.60. The average values recorded via view inputs during DecemberJanuary period were: October 1.44, November 3.41, December 4.40 and January 4.03. Corresponding standard deviation was respectively: October 1.76, November 3.39, December 3.98 and January 4.78 .

The first step was to test the differences of view inputs between the two academic years. Through calculation of the statistical indicators of centrality we obtained the following results:

1. In 2015-2016 the mean value for view inputs was 2.41 ,

2. In 2016-2017 the mean value for view inputs was 3.821

Consequently, the Mann-Whitney test $(U=178, p=0.04<0.05)$ indicated that there exists differences between the number of visits from the two years namely the mean value of view inputs recorded in the second test is greater than the value of view inputs from the first year. In this context we analysed each month to check where the differences are coming from. The test continued with the application of the $\mathrm{U}$ Mann-Whitney test for each month of study and we observed that the number of view inputs significantly increases in the second year only in October, November and December that concludes that the desire of students to get involved increased from one year to another.

Table 1. View comparison of the two years of study

\begin{tabular}{|c|c|c|c|c|}
\hline Year of Study & Month & Average & Stdev & $\begin{array}{l}\text { U-Mann- } \\
\text { Whitney }\end{array}$ \\
\hline $2015-2016$ & \multirow{2}{*}{ October } & 0.87 & 1.256 & \multirow{2}{*}{$\begin{array}{c}U=6406.000 ; \\
p=0.012\end{array}$} \\
\hline $2016-2017$ & & 1.44 & 1.763 & \\
\hline $2015-2016$ & \multirow{2}{*}{ November } & 2.23 & 1.912 & \multirow{2}{*}{$\begin{array}{c}U=6638.000 ; \\
p=0.04\end{array}$} \\
\hline $2016-2017$ & & 3.91 & 1.395 & \\
\hline $2015-2016$ & \multirow{2}{*}{ December } & 3.23 & 1.725 & \multirow{2}{*}{$\begin{array}{c}U=6460.00 \\
p=0.027\end{array}$} \\
\hline 2016-2017 & & 4.40 & 1.988 & \\
\hline $2015-2016$ & \multirow{2}{*}{ January } & 3.75 & 1.074 & \multirow{2}{*}{$\begin{array}{c}U=6883.000 \\
p=0.139\end{array}$} \\
\hline $2016-2017$ & & 4.03 & 2.785 & \\
\hline
\end{tabular}


From the above table we could observe that in the second year, students show interest in getting involved right from the first month. In January, the interest has increased in both years. This is justified by the fact the January is the month designated for practical exams.

Statistical analysis imposed the application of the Kruskal-Wallis test for independent and unequal samples in the two years of study. The hypothesis we have tested is: There exist differences in the desire to study the database theory given by the student's desire in the online activity. The student's implication degree could be measured by the number of view inputs generated by them. After the study we have observed that in both years there exist three categories of students. From the first year of study we observed that we have students with a low activity with an average of 4 visits/month, students with average activity with 8-10 visits/month and students with high activity with more than 10 visits per month. The resulting statistical result is 9.94 based on a $p$ value $<0.01$ with 3 freedom degrees which means that we dismiss the hypothesis of null test and we obtain that the differences between the categories in terms of the degree of processing information / material provided by course and therefore in terms of the degree of knowledge assimilated during the semester.

In further study, we tried to determine the existence / non-existence of a correlation between the number of view inputs and number of messages for each category of student identified. The result obtained and interpreted according to Colton (1974) (T. Drugan, et all) is as follows:

For the first year of study:

1. In the student's category with low activity with an average of 4 visits / month we computed the Pearson Bavaris' correlation coefficient and we obtained $r=0.37<0.5$ which means a weak correlation with low degree of association. The regression line that approximates the tendency of the dot cloud is based on the equation: $y=0.86 x+$ 305.4 and of the coefficient of determination $R^{2}=0.045$. This equation has a very low level of trust, with a coefficient of determination of only 0.136 , which means that there is a correlation between the activities only for three users in a hundred.

2. In the student's category with average activity of 8-10 views / month the Pearson correlation coefficient is $r=0.768$ which means a good correlation between view inputs and messages. The regression line that approximates the tendency of the dot cloud is based on the equation $y=6.762 x+145$ and the coefficient of determination $R^{2}=0.589$. The trust level of this equation is good, with a coefficient of determination of 0.589 , which means that there is a correlation between the two activities for six users in ten for this group. 
3. In the category with a high activity, i.e. more than 12 visits / month, the Pearson correlation coefficient was $r=0.45<0.50$ which is a mean to weak correlation with a low degree of association as shown in the below table and chart. The regression line approximating the tendency of the dot cloud is based on the equation: $y=0.361 x+$ 276.61 and on the coefficient of determination $R^{2}=0.456$. The level of trust of this equation is very low, with the coefficient of determination being 0.207 , which means that there is a correlation for the two activities for two users in te for this group.

For the second year of study:

1. In the student's category with a low activity with a mean value of 6 visits / month, the Pearson Bavaris' correlation coefficient is $r=0.40<0.50$ which means a weak correlation with low degree of association. The regression line that approximates the tendency of the dot cloud is based on the equation: $y=0.83 x+405.4$ and of the coefficient of determination $\mathrm{R}^{2}=0.16$. This equation has a very low level of trust, with a coefficient of determination of only 0.2 , which means that there is a correlation between the two activities only for three users in a hundred.

2. In the second category with 8-12 visits / month, the Pearson correlation coefficient is $r=0.787$ which means a good correlation between view and messages. The regression line that approximates the tendency of the dot cloud is based on the equation $y=6.962 x+245$ and the coefficient of determination $R^{2}=0.619$. The trust level of this equation is good, with a coefficient of determination of 0.619 , which means that there is a correlation between the two activities for six users in 12 for this group.

3 . In the third category with high activity with more than 12 visits / month, the Pearson correlation coefficient was $r=0.48<0.50$ which is an average to weak correlation with a low level of association as presented in the below table and chart. The regression line approximating the tendency of the dot cloud is based on the equation: $y=0.361 x+276.61$ and on the coefficient of determination $R^{2}=0.389$. The level of trust of this equation is very low, with the coefficient of determination being 0.23 , which means that there is a correlation for the two activities for three users in ten for this group.

\section{Conclusions}

We consider the results of the analysis encouraging since the students accept and engage in the new teaching environment created through the usage of web 2.0 tools. This gives us the desire to continue the research further on in order to have an overview of the student's behavior in this environment. Though small-scale the present study may be considered as evidence that Web 2.0 tools can be used successfully in 
higher education, in particular for participation and response to digital economic theory. However, in addition it is required a regular observation of both classroom and online participation to confirm the results of this study and to improve the interaction of Moodle's participants. Further, our research will focus on more in-depth analysis of how the new learning environment can support a systematic and efficient acquisition of databases theory to facilitate collaborative skills of students. Therefore, we decided to conduct a content analysis on various products of individual and collaborative work performed on Moodle and to analyze, compare patterns of participation-interaction (teacher-student, student-student) resulting from such web 2.0 environment.

\section{Works Cited}

C.C. Aydin, G. Tirkes, Open source learning management systems in e-learning and Moodle, In Proceedings of IEEE EDUCON, IEEE Engineering Education (2010) pp:593-600.

S. Bianchi, G. Vercelli, G. Vivanet, Digital Libraries and Educational Resources: the AquaRing Semantic Approach, International Journal of Emerging Technologies in Learning (iJET), Vol5(1) (2010),pp:16-23.

K. Brandl, Are you ready to "Moodle"?, Language Learning \& Technology, 9,(2005) pp:16-23.

Coccoli, M., Vercelli, G., Vivanet, G., Semantic Moodle for learning and teaching computer science, Focus on: e- Learning: Requirements of the disciplines, Vol. 9( 2) (2013), pp:169-179;

S. Bansode, R. Kumbhar, E-learning Experience using Open Source Software: Moodle, Journal of Library \& Information Technology, Vol. 32, No. 5, (September 2012), pp. 409-416.

C. Bereiter, M. Scardamalia, Intentional learning as a goal of instruction, Knowing, learning, and instruction: Essays in honor of Robert Glaser (1989): 361-392.

K. Brandl, Are you ready to Moodle. Language Learn. Technol., 9(2),(2005),pp: 1623.

D.L. Davids, "Recovery effects in binary aluminum alloys", Ph.D. thesis, Harvard University, (1998).

T. Drugan, A. Achimas, S., Tigan, "Biostatistică", Editura SRIMA, Cluj-Napoca, ISBN:973-85285-5-0. (2005);

***, Moodle. About Moodle. Access: http://docs.moodle.org/22/ en/About_Moodle. 
P. Griffin, B. McGaw, E. Care, "Assessment and teaching of 21st Century skills" New York, NY: Springer, (2012).

A. Giordan, G., De Vecchi, Les origines du savoir. Des conceptions des apprenants aux concepts scientifiques. Neuchatel: Delachaux \& Niestlé, (1987).

D.J. Gilmore, Expert programming knowledge: $A$ strategic approch., In J.M.Hoc, T.R.G. Green, R. Samurcay \& D.J. Gillmore (Eds), Psychology of programming, London: Academic Press (2009).

G. Grosseck , To Use or Not to Use Web 2.0 in Higher Education?, Communication at the World Conference on Educational Sciences 2009, Procedia Social and Behavioral Sciences 1, pp: 478-482 (2009),webpages.csus.edu/ sac43949/ PDFs/tousenottouse.pdf

C. A. Hicheur, B. Gueni, M. Fhima, A. Cairms, S. David, N. Khelifa Process Mining in Educational Domain, International Journal on Advances in Intelligent Systems, Vol 8, No 1 \& 2, (2015) pp:219-232.

C. Felea, L. Stanca, Moodle Tools in Teaching English for Academic Purposes - An Analysis of Student Learning Behaviour Pattern. "Carol II" National Defence University Publishing House. Vol. 1, (2013) pp:82-91.

C. Felea, L. Stanca, Moodle Tools in Teaching English for Academic Purposes - IT and Language Proficiency as Predictors of Online Participation., "Carol I" National Defence University Publishing House, Vol 3, (2014) pp: 312-321.

R. Lacurezeanu, R. Buchmann, P. Bresfelean, A. Valerica, The Place of e-Learning in Romanian Universities' Strategies, Informatica Economica 15(1), pp:220-227 (2011).

A.M. Preda, J.L. Stanica, D.A. Crisan, A study on the stage of e-learning development in Romania. In: European Integration-New Challenges, 6th ed. (2010).

${ }^{* * *}$ Intel. Raport de evaluare a studiului national. Tendinte în utilizarea ICT de cãtre student români, Bucuresti, România (2009).

F. Paragina, et al. The benefits of using MOODLE in teacher training in Romania, Procedia Soc. Behav. Sci., Vol 15, (2012),pp:1135-139.

S. Paragina, et al. The Moodle course management system and its e-learners' needs, Procedia Soc. Behav. Sci., 15, (2011), pp:1135-139.

E. Popescu, D., Cioiu, eMUSE - Integrating Web 2.0 Tools in a Social Learning Environment, Springer, Heidelberg LNCS, vol. 7048, pp. 41-50. (2011).

T. Escobar-Rodriguez, P., Monge-Lozano, The acceptance of Moodle technology by business administration students, Computers \& Education, (2011). www. sciencedirect.com/science/article/ pii/S0360131511002934. 
P. Subramanian ,N., Zainuddin ,S. Alatawi , A Study of Comparison between Moodle and Blackboard based on Case Studies for Better LMS, Journal of Information Systems Research and Innovation, www.moodlebites.com/pluginfile.php/26295/mod_resource/content/1/Pub4_ ComparisonBetweenMoodleAnd Blackboard.pdf

S. Bansode, R. Kumbhar, E-learning Experience using Open Source Software: Moodle, Journal of Library \& Information Technology, Vol. 32, No. 5, (September 2012), pp. 409-416.

A. Bullimore, Q. Bullimore, Creating the strategic learning environment at City University London, Campus- Wide Inf. Sys., Vol 28(4), (2001),pp:275-88.

M.A. Trenas, et al. Use of a new Moodle module for improving the teaching of a basic course on computer architecture. IEEE Trans. Edu., Vol:54(2), (2001),pp: 22228.

M. Machado, E. Tao, Blackboard vs. Moodle: Comparing user experience of Learning Management Systems, Proceedings of the 37th ASEE/IEEE Frontiers in Education Conference (pp. S4J-7 - S4J-12). IEEE. Retrieved March 23, 2009.

M., Miled, Un cadre conceptuel pour l'élaboration des curriculums selon l'approche par les compétences. În: La refonte de la pédagogie en Algérie - Défis en enjeux d'une société en mutation. Alger: UNESCO - ONPS, (2005) p. 125-136

Mukala, P., Buijs, J., and van der Aalst, W., Exploring students' learning behaviour in moocs using process mining techniques.; (2015)Tech. rep., Technische Universiteit Eindhoven.

M. Pechenizkiy, T. Calders, E. Vasilyeva, P. De Bra, Mining the student assessment data: Lessons drawn from a small scale case study, Proc. Int. Conf. Educ. Data Mining, (2008), pp:187-191.

M. Pechenizkiy, N. Trčka, E. Vasilyeva, W. van der Aalst, P. De Bra, Process Mining Online Assessment Data, Proc. Int. Conf. Educ. Data Mining, (2009),pp:279-288.

W. J. Strijbos, "Assessment of (computer-supported) collaborative learning", IEEE Transactions on Learning Technologies, vol. 4(1),(2011), pp.59-73.

A. Radloff, "Engaging staff in quality learning and teaching: What's a ProVice Chancellor to do? In Engaging Communities", Proceedings of the 31st HERDSA Annual Conference, (2008), pp. 285-296. 